\title{
Intra- and Inter-rater Reliabilities of Infrasternal Angle Measurement
}

\author{
Moon-Hwan Kim¹, Jong-Hyuck Weon ${ }^{2}$ \\ 'Department of Physical Therapy, The Graduate School, Yonsei University, Wonju; ${ }^{2}$ Department of Physical Therapy, College of Tourism \& Health \\ Science, Joongbu University, Geumsan-gun, Chungnam, Korea
}

Purpose: The purpose of this study was to propose a new reference point for measurement of the infrasternal angle and to investigate the intra- and inter-rater reliabilities of infrasternal angle measurement using photographs.

Methods: Twenty-four healthy male college students participated as subjects in this study. Photographs were taken of subjects in two postures, one standing with the shoulders relaxed and one standing with the shoulders at $150^{\circ}$ abduction. All photographs were analyzed using Image J software. Raters used the photographs to measure the infrasternal angle between the xiphoid process, the medial margin of rib and navel on the right and left sides. The reliability of the infrasternal angle measurement was assessed by means of intraclass correlation coefficients [ICC $(3,1)]$. The level of statistical significance was set at $p<0.05$.

Results: The intra- and inter-rater reliabilities of the infrasternal angle measurement for the right side at rest were excellent (ICC $=0.866$ and 0.813 , respectively), as were those for the left side at rest (ICC $=0.919$ and 0.846 , respectively). At $150^{\circ}$ shoulder abduction, the intra- and inter-rater reliabilities for measurement of the infrasternal angle on the right side were excellent $(\mathrm{ICC}=0.972$ and 0.778 , respectively), as were those for the left side (ICC $=0.914$ and 0.826 , respectively).

Conclusion: These findings suggest that this technique can be successfully used to measure the infrasternal angle, thus suggesting a new reference point for determining the length of the internal oblique and external oblique muscles in clinical situations.

Keywords: Thoracic rotation syndrome, Infrasternal angle, Photograph

\section{INTRODUCTION}

The thorax is composed of stable structures including the thoracic vertebrae, ribs, and sternum. ${ }^{1}$ These stable structures aid in maintaining breathing, protect internal organs such as the heart and lungs, and support attachments of trunk muscles. ${ }^{2-4}$ The thoracic vertebrae are able to move in several directions; especially notable is their degree of rotation $\left(40-55^{\circ}\right)$ compared with the lumbar vertebrae. ${ }^{2,5}$ Rotation of the thoracic vertebrae occurs when the rib cage is rotated, and repetitive and sustained rotation of the thoracic vertebrae or scoliosis associated with the thoracic vertebrae can have an effect on the movement or alignment of the rib cage. ${ }^{6-9}$

Thoracic rotation syndrome is typified by pain related to repeti-

Received May 28, 2015 Revised Jun 11, 2015

Accepted Jun 18, 2015

Corresponding author Jong-Hyuck Weon

E-mail whyuck@hanmail.net tive and sustained rotational movement and rib cage asymmetry associated with thoracic rotation in the sagittal plane. ${ }^{6}$ Asymmetry of the rib cage affects recruitment of the abdominal muscles and influences the length of the internal oblique and external oblique muscles bilaterally. ${ }^{10-12}$ In a previous study, asymmetrical length of the internal and external oblique muscles between the right and left sides resulted in limitations to trunk rotation. ${ }^{13}$ Asymmetry of oblique muscle may be occurred asymmetric activation of oblique muscle, these asymmetric activation can led to pain, causing microtrauma-related tissue inflammation around the facet joints. ${ }^{14}$ Therefore, assessment of rib cage differences between the right and left sides is important to identify subjects with thoracic rotation syndrome. $^{6}$
Copylight ( 92015 The Korea Society of Physical Therapy

This is an Open Access article distribute under the terms of the Creative Commons Attribution Non-commercial License (Http:// creativecommons.org/license/by-nc/3.o.) which permits unrestricted non-commercial use, distribution, and reproduction in any medium, provided the original work is properly cited. 
In a clinical situation, rib cage symmetry is commonly assessed by measuring the infrasternal angle, which requires calculating the angle between the xiphoid process and the medial margin of the rib on each side. ${ }^{6}$ A previous study reported that the ideal infrasternal angle was $90^{\circ}$, as that value reflected a balance between the internal oblique and external oblique muscles. ${ }^{6}$ If the internal oblique muscle is contracted or shortened bilaterally, the infrasternal angle becomes wider than this ideal, whereas if the external oblique muscle is contracted or shortened bilaterally, the infrasternal angle is narrower. ${ }^{6,15}$ Furthermore, in individuals with perpetual rotation toward one side, the infrasternal angles of the right and left side differ due to length changes in the internal and external oblique muscles. ${ }^{6}$

Thus, measurement of the infrasternal angle is a useful method for identifying the length of the internal and external oblique muscles. However, the inter-rater reliability of infrasternal angle was reported to be low, with testers apparently obtaining differing values due to the curved shape of the medial margin of the rib. ${ }^{6}$ The low inter-rater reliability of infrasternal angle measurement has rendered it inadequate as a 'gold standard' for identifying thoracic rotation syndrome and determining the length of the internal and external oblique muscles. Therefore, the purpose of this study was to suggest a reference point for the infrasternal angle and to investigate the intra- and inter-rater reliability of measurements using this reference point.

\section{METHODS}

\section{Subjects}

In this study, 24 healthy subjects (all male) were recruited from among students at $Y$ University, Wonju-si. Exclusion criteria were any neuromuscular disorder, cardiopulmonary disorder, congenital disorder of the trunk or lower extremities, scoliosis, fracture of the ribs or xiphoid process, subject with thoracic or lumbar rotation syndrome, and limitation of bilateral shoulder flexion. All subjects participated voluntarily in this study. Before the study, the investigator explained the experimental procedures to the subjects. Characteristics of the subjects are presented in Table 1.

\section{Experimental methods}

The study was conducted by two testers and one assistant. Tester 1 was a physical therapist who has worked in a general hospital for 10
Table 1. General characteristics of subjects

$(N=24)$

\begin{tabular}{lrc}
\hline & \multicolumn{2}{c}{ Subject } \\
\cline { 2 - 3 } & Mean \pm SD & Range \\
\hline Age (year) & $22.9 \pm 1.8$ & $20.0-22.0$ \\
Height $(\mathrm{cm})$ & $173.5 \pm 1.4$ & $152.0-183.0$ \\
Weight $(\mathrm{kg})$ & $70.6 \pm 2.7$ & $46.0-100.0$ \\
\hline
\end{tabular}

SD, standard deviation.

years, tester 2 was a sophomore student in the Department of Physical Therapy, and the assistant was a graduate student in the Department of Physical Therapy. Prior to the study, the testers and assistant became acquainted with the technique for measuring the infrasternal angle and with the experimental procedures.

The infrasternal angle was measured with the subject in two positions. Subjects were measured first in a relaxed standing position and then in a standing position with $150^{\circ}$ shoulder abduction. Subjects were instructed to breathe comfortably during measurement. For the infrasternal angle measurement, first, we suggested the reference point of medial margin (a perpendicular line was drawn from the mid clavicle to the medial margin of the rib cage). Markers were attached on the xiphoid process, navel, and the reference point of medial margin. An angle formed between two lines were measured. The two lines formed an angle for measurement. (One line: the line connecting the xiphoid process and the navel, the other line: the line connecting the xiphoid process and medial margin of rib cage) (Figure 1).

After the markers were attached, the assistant took photographs from a position $1.5 \mathrm{~m}$ in front of the subject using a camera $(450 \mathrm{D}$, Cannon, Inc., Japan). The tester measured each subject twice in each position; the order of subjects and positions were randomized.

The assistant then analyzed each photograph using Image J software (National Institutes of Health, Bethesda, MD, USA). To do this, the assistant drew a line on the image from the xiphoid process to the navel, and then drew lines from the xiphoid process to the markers indicating the medial margin of the 10th rib on both sides. The right and left sides of the infrasternal angle were calculated as the angle formed by the line connecting the markers on the xiphoid process and the navel and the line connecting the markers on the xiphoid process and medial margin of the 10th rib. Intra-rater reliability was calculated based on the measurement values obtained by tester 1 , and the inter-rater reliability was calculated by comparing the first trial values of tester 1 and tester 2 . 

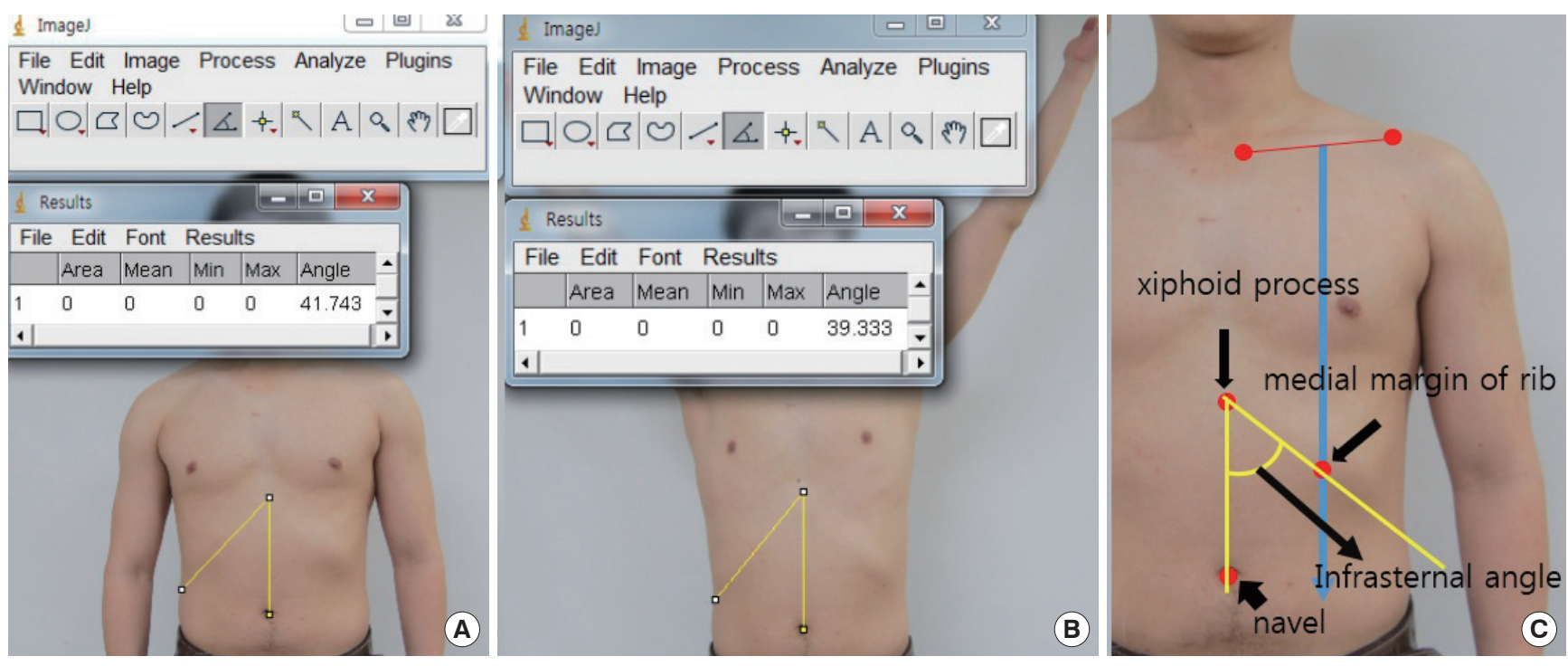

Figure 1. Measurement of infrasternal angle using image J software program. (A) In resting position, (B) In shoulder abduction 150 , (C) Landmark of measurement.

Table 2. Mean and standard deviation of infrasternal angle $\quad(\mathrm{N}=24)$

\begin{tabular}{lccccc}
\hline & \multicolumn{2}{c}{ In rest standing posture } & & \multicolumn{2}{c}{ In standing posture } \\
& \multicolumn{2}{c}{} & & with $150^{\circ}$ shoulder abduction \\
\cline { 2 - 3 } \cline { 5 - 6 } & Right side & Left side & & Right side & Left side \\
\hline Tester 1 & $35.57 \pm 5.83$ & $40.00 \pm 5.55$ & & $34.76 \pm 5.86$ & $39.64 \pm 5.26$ \\
Tester 2 & $38.07 \pm 6.01$ & $39.81 \pm 5.88$ & & $34.85 \pm 5.99$ & $36.90 \pm 5.96$ \\
\hline
\end{tabular}

Table 3. Intra-rater reliability of infrasternal angle

$(\mathrm{N}=24)$

\begin{tabular}{lccccc}
\hline & \multicolumn{2}{c}{ In rest standing posture } & & \multicolumn{2}{c}{ In standing posture } \\
& \multicolumn{2}{c}{ with $150^{\circ}$ shoulder abduction } \\
\cline { 2 - 3 } \cline { 5 - 6 } & Right side & Left side & & Right side & Left side \\
\hline ICC $(3,1)$ & 0.866 & 0.919 & & 0.972 & 0.914 \\
$(95 \%$ Cl $)$ & $(-4.62-2.32)$ & $(-5.24-1.41)$ & & $(-4.16-3.58)$ & $(-3.72-2.72)$ \\
SEM & 2.14 & 1.58 & & 0.98 & 1.54 \\
\hline
\end{tabular}

ICC, intraclass correlation coefficients; Cl, confidence interval; SEM, standard error of measurement.

\section{Statistical analysis}

The subject's characteristics and the infrasternal angle of the right and left sides are presented as means and standard deviations (SD). A repeated-measures analysis of variance (ANOVA) with a post hoc t-test was used to test for systematic bias between the first and second measurements. Intraclass correlation coefficients [CC $(3,1)]$ were used to determine the inter- and intra-rater reliabilities of the infrasternal angle measurement on the right and left sides. The standard error of measurement (SEM) was calculated for each measurement to assess absolute consistency. ${ }^{16}$ Statistical analyses were performed using the Statistical Package for the Social Sciences version 21.0 for Windows (SPSS, Inc., Chicago, IL, USA). The signifi-
Table 4. Inter-rater reliability of infrasternal angle

$(N=24)$

\begin{tabular}{lccccc}
\hline & \multicolumn{2}{c}{ In rest standing posture } & & \multicolumn{2}{c}{ In standing posture } \\
& \multicolumn{2}{c}{ with $150^{\circ}$ shoulder abduction } \\
\cline { 2 - 3 } \cline { 5 - 6 } & Right side & Left side & & Right side & Left side \\
\hline ICC $(3,1)$ & 0.813 & 0.846 & & 0.778 & 0.826 \\
$(95 \% \mathrm{Cl})$ & $(-6.10-1.10)$ & $(-3.29-3.37)$ & & $(-3.70-3.52)$ & $(-0.67-6.16)$ \\
SEM & 2.52 & 2.18 & & 2.76 & 2.19 \\
\hline
\end{tabular}

ICC, intraclass correlation coefficients; Cl, confidence interval; SEM, standard error of measurement.

cance level was set at $\mathrm{p}<0.05$.

\section{RESULTS}

The measurement values of the infrasternal angle for testers 1 and 2 was shown the mean \pm SD (Table 2). The intra-rater reliabilities for measurement of this angle on the right and left sides were 0.866 and 0.919 , respectively, in the resting position, and 0.972 and 0.914 , respectively, with $150^{\circ}$ shoulder flexion (Table 3).

Inter-rater reliabilities for measurement of the infrasternal angle on the right and left sides were 0.813 and 0.846 , respectively, in the resting position, and 0.778 and 0.826 , respectively, with $150^{\circ}$ shoulder flexion (Table 4).

\section{DISCUSSION}

Although measurement of the infrasternal angle has been a common method for identifying thoracic rotation syndrome and assess- 
ing the balance of abdominal muscle, it has been reported to have low inter-rater reliability. ${ }^{6}$ Therefore, we suggested a reference point for measuring the infrasternal angle and calculated intra- and interrater reliability by analyzing photographs.

The present study demonstrated excellent intra- and inter-rater reliability ( 0.866 and 0.778 or higher, respectively) for measurements with and without $150^{\circ}$ shoulder flexion. Tester 1 was a physical therapist, and tester 2 was sophomore student. Although tester 2 lacked measurement experience, we nevertheless found excellent inter-rater reliability following training in the measurement method. Thus, if physical therapists working in clinical settings are taught this method of measuring the infrasternal angle, they should be able to perform the assessment with comparative ease.

For tester 1, the mean infrasternal angles on the right and left sides were $35.57^{\circ} \pm 5.83^{\circ}$ and $40.00^{\circ} \pm 5.55^{\circ}$, respectively, and in tester 2 , they were $38.07^{\circ} \pm 6.01^{\circ}$ and $39.81^{\circ} \pm 5.88^{\circ}$, respectively. The mean differences between tester 1 and tester 2 were $2.50^{\circ}$ and $0.19^{\circ}$ for the right and left sides, respectively, without shoulder abduction. With $150^{\circ}$ shoulder abduction, the differences in mean values between testers 1 and 2 were $0.09^{\circ}$ and $2.74^{\circ}$ for the right and left sides, respectively (Table 2). The mean difference between measurements with and without shoulder abduction was less than $3^{\circ}$; this value was not significantly different between testers 1 and 2 . If an infrasternal angle of $90^{\circ}$ is considered ideal, 6 then the infrasternal angle of subjects in the present study was narrower than ideal, suggesting a dominant external oblique relative to the internal oblique muscle. Also, measurements in this study indicated that $150^{\circ}$ shoulder abduction decreased the right and left infrasternal angles slightly (by 0.81 and 0.36 , respectively). Shirmann (2011) reported no difference in the infrasternal angle between a standing position with and one without shoulder abduction, 6 similar to the results presented here.

Little research has been carried out on the infrasternal angle. Because X-rays do not show the infrasternal angle, no study has yet evaluated the validity of infrasternal angle measurement. Because $\mathrm{X}$-rays can't use for measuring infrasternal angle, we take advantage of photography in this study. In previous study, intra- and interrater reliability are showed high correlation between radiographic and photographic measurement. ${ }^{17}$ Also, other researcher suggested that photographic measurement used when it was difficult to use the $\mathrm{X}$ ray measurement. ${ }^{18}$ Therefore, this study evaluating the reliability of such measurement is important. Limitations of the present study include low generalizability because the inclusion criteria limited the sample to males in their 20s who had experienced no neuromuscular or musculoskeletal problems. Further research, preferably using electromyography, will be helpful in determining differences in muscle activity between the internal and external oblique muscles in subjects with asymmetrical infrasternal angles.

\section{REFERENCES}

1. Koumbourlis AC. Chest Wall Abnormalities and their Clinical Significance in Childhood. Paediatr Respir Rev. 2014;15(3):246-54.

2. Neumann DA. KINESIOLOGY of the MUSCULOSKELETAL SYSTEM. St. Louis, Mosby, 2002:369-70.

3. Magee DJ. Orthopedic Physical Assessment. 4th edition. Saunders. Philadelphia. 2002:425-44.

4. De Troyer A, Wilson TA. Mechanism of the increased rib cage expansion produced by the diaphragm with abdominal support. J Appl Physiol (1985). 2015;118(8):989-95.

5. Johnson KD, Kim KM, Yu BK, et al. Reliability of thoracic spine rotation range-of-motion measurements in healthy adults. J Athl Train. 2012; 47(1):52-60.

6. Shirmann S. MOVEMENT SYSTEM IMPAIRMENT SYNDROMES of the Extremities, Cervical and Thoracic Spines. St. Louis, Mosby, 2011:114-37.

7. Campbell RM Jr, Smith MD, Mayes TC, et al. The characteristics of thoracic insufficiency syndrome associated with fused ribs and congenital scoliosis. J Bone Joint Surg Am. 2003;85(3):399-408.

8. Kang JI, Jung DG, Park SK, et al. Forced expiratory volume in one second, Chest resistance exercise, Proprioceptive neuromuscular facilitation. J Kor Phys Ther. 2011;23(2):37-43.

9. Linek P, Saulicz E, Wolny T, et al. Ultrasound evaluation of the symmetry of abdominal muscles in mild adolescent idiopathic scoliosis. J Phys Ther Sci. 2015;27(2):465-68.

10. Kim BK, Lee MH, Kim GC. Comparison of Abdominal Muscle Activity during Exercises Using a Sling and Swiss-ball. J Kor Phys Ther. 2012; 25(3):149-54.

11. Lim JH. Correlations of Symmetry of the Trunk Muscle Thickness by Gender with the Spinal Alignment in Healthy Adults. J Kor Phys Ther. 2013;25(6):405-10.

12. Kang HK, Chang SK. The Effect of Robo-horseback Riding Exercise on Trunk Muscle Activity Ratios in Patients with Low Back Pain. J Kor Phys Ther. 2012;24(6):393-7.

13. Richardson C, Hodges PW, Hides J. Therapeutic Exercise for Lumbopelvic Stabilization: A Motor Control Approach for the Treatment and Prevention of Low Back Pain. 2nd ed. London. Churchill Livingstone. 2004.

14. Vera-Garcia FJ, Brown SHM, Gray JR, et al. Effects of different levels of torso coactivation on trunk muscular and kinematic responses to posteriorly applied sudden loads. Clinical Biomechanics 2006;21(5):443-55.

15. Kendall FP, McCreary EK, Provance PG, et al. Muscles: Testing and function with posture and pain. 5th ed. Baltimore, MD, Williams \& Wilkins,2005:200-1. 
TPTT $\begin{aligned} & \text { The Journal of } \\ & \text { Korean Physical Therapy }\end{aligned}$

16. Shrout PE, Fleiss JL. Intraclass correlations: Uses in assessing rater reliability. Psychol Bull. 1979;86(2):420-8.

17. Nix S, Russell T, Vicenzino B, et al. Validity and reliability of hallux valgus angle measured on digital photographs. J Orthop Sports Phys Ther.
Moon-Hwan Kim and Jong-Hyuck Weon

2012;42(7):642-8.

18. Choung SD, Kang SY, Kim MH, et al. Reliability and validity of the goniometer for hallux valgus angle measurement. Phys Ther Kor. 2013; 20(2):46-51. 